\title{
A Prática da Autoavaliação no Ensino Superior
}

\author{
Ivan do Nascimento Freire Lopes ${ }^{1}$
}

\begin{abstract}
Resumo: Este artigo teórico faz parte de pesquisas desenvolvidas com a Universidad de Santiago de Chile e a UniLeão-Centro Universitário. Intitula-se: A prática da Autoavaliação no Ensino Superior. Ocorre portanto a intenção de analisar as metodologias de escolha dos professores pela Autoavaliação, como ferramenta avaliativa e de autorregulação dos processos de aprendizagem e ensino, detalhando práticas específicas como ferramenta. A princípio buscou-se investigar os principais estudiosos sobre conceitos, tipos e categorias e intenções da avaliação educacional, além de estudar como está a prática de autoavaliação no ensino superior, de acordo com a Legislação Brasileira e, finalmente, sinalizar como algumas ações adotadas por educadores influem no próprio fazer pedagógico. A metodologia de nosso estudo é de enfoque Fenomenológico, com técnica descritiva, explicativo, fortalecido por estudo de caso em seu desenho metodológico. Os sujeitos da pesquisa foram professores universitários desta IES. Os instrumentos de coleta foram questionários a professores de ensino superior e posteriormente, deste mesmo grupo um quantitativo a aplicação de entrevistas. Os dados parciais também revelam em linhas gerais que este estudo representa a possibilidade de tornar mais explícito o conhecimento e análise de como os professores pensam, vivenciam e concebem ao adotar a prática autoavaliativa como experiência de autoconhecimento. Desse modo uma questão se coloca como ponto chave: como os professores encaram e interpretam os momentos de autoavaliação diante dos processos entre como avaliam e são avaliados.
\end{abstract}

Palavras-chave: Avaliação Educacional. Autoavaliação. Ensino Superior.

\section{The Practice of Self-Assessment in Higher Education}

\begin{abstract}
This theoretical article is part of researches developed with the University of Santiago de Chile and UniLeão-Centro Universitário. It is entitled: The practice of Self-Assessment in Higher Education. Therefore, the intention is to analyze the methodologies of choice of teachers by the Self-assessment, as an evaluation tool and self-regulation of learning and teaching processes, detailing specific practices as a tool. At first, we sought to investigate the main scholars about concepts, types and categories and intentions of the educational evaluation, as well as to study how the practice of self-assessment in higher education, according to the Brazilian Legislation is, and finally to indicate how some actions adopted by educators influence their own pedagogical practice. The methodology of our study is a Phenomenological approach, with descriptive, explanatory technique, strengthened by case study in its methodological design. The subjects of the research were university professors of this HEI. The collection instruments were questionnaires to higher education teachers and later, from this same group a quantitative the application of interviews. Partial data also reveal in general terms that this study represents the possibility of making explicit the knowledge and analysis of how teachers think, experience and conceive when adopting the self-assessment practice as an experience of self-knowledge. In this way, a question becomes a key point: how the teachers view and interpretate the moments of self-evaluation in the processes between how they evaluate and are evaluated.
\end{abstract}

Keywords: Educational Evaluation. Self-evaluation. Higher education.

\footnotetext{
${ }^{1}$ Mestre em Avaliação pela USACH-Universidad de Santiago do Chile. Possui graduação em Letras pela URCA Universidade Regional do Cariri, especialização em Língua Portuguesa pela mesma instituição. Especialista em Docência do Ensino Superior pela Universidade Castelo Branco do Rio de Janeiro UCB/RJ. Professor multiplicador da Rede Salesiana de Escolas, Elaborador de Itens (Edebê Brasil). Professor Universitário da UniLeão. Professor Efetivo da Rede Municipal de Ensino Público de Juazeiro do Norte, Ceará. Graduando em Pedagogia. Contato: ivan.do.nascimento@gmail.com.
} 


\section{Introdução}

Chega um momento em que todas as atividades docentes se esgotam. O professor comprometido com sua prática angustia-se e questiona-se: E agora? O que posso fazer? Esta frase de efeito tão simples é cotidiana em estudos acadêmicos e em vivências educativas no trabalho docente. E não é exclusividade do ensino básico - também faz parte das conversas entre professores universitários, em intervalos, na sala dos professores - o verdadeiro muro de lamentações e de trocas de experiências que envolvem ensino e aprendizagem também.

O presente estudo apresenta a reflexão de uma prática adotada: o DIARIO DE BORDO como ferramenta de autoavaliação utilizada como parte do processo avaliativo docente e discente. Fernandes (2008) escreve que "A autoavaliação ainda não faz parte da cultura escolar brasileira. Entretanto, se quisermos sujeitos autônomos, críticos, devemos ter consciência de que tal prática deve ser incorporada ao cotidiano dos planejamentos dos professores, do currículo, por fim.” (p.35). A discussão sobre autoavaliação, ao que cremos, para o Brasil, é inovadora, pertinente e necessária. Justamente por isso, alguns estudiosos são necessários: Perrenoud (1999), Hadji (2001), Condemarin e Medina (2007), Luckesi (2011), Masetto (2004), Grochoska (2013), Brandalise (2010), Moretto (2010) além de autores que surgiam durante a nossa construção teórica.

"Pesquisar basicamente é encontrar soluções para problemas propostos" (Lakatos, 2001:43) então caracteriza-se quanto a abordagem qualitativa. Seu nível é "explicativo" Gil (2002:41-57). Sua tipologia é exploratória, "tipo de pesquisa que objetiva dar uma explicação geral sobre determinado fato, através da delimitação do estudo, levantamento bibliográfico, leitura e análise de documentos" Gil (2002:41-57). Seus procedimentos caracterizam-na como pesquisa de campo, na observação dos fatos tal como ocorrem na realidade, diretamente no local onde ocorrem os fenômenos. Em sequência buscamos em nossa pesquisa: a. Conhecer como os contextos das práticas autoavaliativas são escolhidas e utilizadas; b. Classificar tipos de autoavaliação escolhidos para a execução no processo; c. Comparar modelos de autoavaliação utilizadas em sala de aula e d. Analisar a forma da autoavaliação colaborar na avaliação dos professores de ensino superior. 


\section{Referencial Teórico}

No início do século XIX desenvolvem-se investigações nas escolas sobre avaliação. Tyler conceitua o foco da avaliação baseada em objetivos, instrumentos e procedimentos de medida. Entre os anos de 1946-1957 não é possível avaliar tudo que se aprende e, portanto melhora-se o desenho (organização) e técnicas de medida.

Nos anos 1950 Chronbach (1958-72) percebe que avaliação não é somente técnica, também vista como política. Surgem novos modelos e em seguida, a avaliação não tem verdade absoluta - ela depende da ótica. Ela passa de medidora para informativa, ajuizada e principalmente tomadora de decisões. No Brasil, existe a prática da autoavaliação institucional para o ensino superior - como formato de CPA - Comissão Própria de Avaliação - burocratizada através da lei, implementada na tentativa de transformar-se em práxis.

Alguns professores utilizam a avaliação 'clássica', mais ainda muito pouco a autoavaliação em seu cotidiano de sala de aula. Existem professores que desvalorizam este tipo de avaliação por acreditar que o aluno não deva fazer juízo do próprio processo de aprendizagem e que avaliar seja ato centralizado no professor. Outros rompem o paradigma e colocam a si e ao outro no processo, desobedecendo felizmente a antiga corrente centralizadora.

Historicamente essa visão foi mudando entre Tyler (1942), pai da avaliação educacional e J. Elliot (1982), este último que propõe o primeiro conceito de autoavaliação. A autoavaliação, que consiste em olhar para si e para o outro, é uma ferramenta que ajuda a identificar muitos problemas de ensino e aprendizagem no processo avaliativo. Historicamente, a avaliação tem várias intenções:

a) Examinar que como diz Luckesi (2003) "é uma tradição dos exames escolares (...) em nossas escolas, sistematizada nos séculos XVI e XVII".

b) Medir que para Hadji (2001), medir "significa atribuir um número a um acontecimento ou a um objeto, de acordo com uma regra logicamente aceitável".

c) Classificar, regular - Nessa perspectiva, "a avaliação é tradicionalmente associada, na escola, à criação de hierarquias de excelência [grifo do autor]" Perrenoud (1999).

d) Qualificar - Na opinião de Esteban (2001), a avaliação qualitativa “configura-se como um modelo em transição por ter como centralidade a compreensão dos processos dos 
sujeitos e da aprendizagem, o que produz uma ruptura com a primazia do resultado característico do processo quantitativo".

A cultura educativa (podemos considerar aqui a práxis) de autoavaliação no Brasil ainda é pouca. Há indícios de pouco uso no ensino superior, e muito pouco em relação ao ensino básico. Este trabalho busca analisar, de forma ousada, a utilização desta prática pouco popularizada e mesmo assim eleita a autoavaliação como parte do processo de ensino e aprendizagem.

No estudo, observou-se um universo de dez (10) professores de ensino superior, de cursos distintos, da UniLeão - Centro Universitário na Cidade de Juazeiro do Norte, Ceará, Brasil. Encontrou-se a práxis do 'Diário de Bordo' como autoavaliação, oportunizando a reflexão sobre quem vivencia a aprendizagem.

Mas as dificuldades metodológicas evidenciadas, sobretudo na utilização da autoavaliação não estão simplesmente ligadas aos alunos. Os professores também convivem com elas. Mesmo assim, tentam reverter o quadro com momentos considerados ímpar na fala do pesquisado. Então, a questão de compreensão sobre a temática está construída soba a ótica da prática do uso do Diário de Bordo: como é eleito, em que momentos, como é realizado, de que forma se cria (ou criam) os instrumentos, que efeitos reproduzem nos estudantes, em que momentos o professor faz uso, no início, meio ou fim do processo? São essas inquietações que nos motivaram a divulgar esta pesquisa. Assim Luckesi (1997) contextualiza dizendo que,

\begin{abstract}
A avaliação da aprendizagem nesse contexto é um ato amoroso, na medida em que inclui o educando no seu curso de aprendizagem, cada vez com qualidade mais satisfatória, assim como na medida em que o inclui entre os bem-sucedidos, devido ao fato de que esse sucesso foi construído ao longo do processo de ensino aprendizagem (o sucesso não vem de graça). A construção, para efetivamente ser construção, necessita incluir, seja do ponto de vista individual, integrando a aprendizagem e o desenvolvimento do educando, seja do ponto de vista coletivo, integrando o educando num grupo de iguais, o todo da sociedade. (LUCKESI, 1997, p.175).
\end{abstract}

Na mesma linha de raciocínio, a avaliação formativa pode atuar sobre o sujeito enquanto aprende e enquanto erra - apresenta os erros, os acertos - faz do processo em relação de partida (início) e chegada (fim) revelando-se uma avaliação com intervenção intrínseca por causa dos envolvidos. Portanto se comprova de modo sistemático na proporção do surgimento dos resultados previstos em seus objetivos/metas. 
Ela não pode atuar apenas em um único âmbito, por exemplo, no âmbito dos estudantes. Atua sobre determinada classe, escola, centro educativo, instrumentos, meios e até mesmo o próprio sistema educacional. Tem um caráter processual e contínuo por permitir aporte sistemático e contínuo dos dados que servem para reorientação de processo e são postos à disposição da avaliação somativa em cada caso. Bloom (1971) informa que "o sentido final das observações formativas (...) é determinar o nível de domínio de uma aprendizagem precisa, e, especificar os aspectos da tarefa que ainda não foram dominados". Esta afirmativa apresenta o pensamento de orientação e reorientação da aprendizagem, segundo o autor.

Podemos pensar: Qual é a lógica de um professor universitário inserir em seu planejamento a prática da autoavaliação? Porque criar então um diário? Como o professor define este diário? Villas Boas (2008:51) auxilia, acrescenta e afirma: “[...] é um componente importante da avaliação formativa". Ele se refere ao processo pelo qual o próprio professor em formação analisa continuamente as atividades desenvolvidas e em desenvolvimento, registra suas percepções e seus sentimentos e identifica futuras ações, para que haja avanço na aprendizagem.

Régnier (1999, p. 03), na autoavaliação faz do aluno em formação se tornar capaz de: i) informar-se sobre sua própria ação ou sobre si mesmo; (ii) regular a ação por si mesmo; (iii) guiar-se por si mesmo na sua ação; (iv) melhorar por si mesmo a eficácia de sua ação. Para este autor a autoavaliação é um processo cognitivo complexo pelo qual um indivíduo (aprendiz, professor) faz um julgamento voluntário e consciente por si mesmo e para si mesmo, com o objetivo dum melhor conhecimento pessoal, da regulação de sua ação ou de suas condutas, do aperfeiçoamento da eficácia de suas ações, do desenvolvimento cognitivo.

Assim, de uma maneira sintética, o uso do diário de bordo envolve competências docentes e discentes, autorreguladoras, fortalecendo o autoconhecimento e especialmente inserindo ambos - professor e alunos - num processo de aprendizes de suas práticas de ensino para o primeiro e aprendizagem para o segundo, com foco nos objetivos previstos anteriormente e na execução dos módulos de aprendizagem. 


\section{Procedimentos Metodológicos}

Como se trata de um recorte de um estudo realizado sobre autoavaliação, em linhas gerais vamos expor aqui sobre a reflexão da prática exposta anteriormente como ferramenta de autoavaliação utilizada como parte do processo avaliativo docente e discente. Assim, traçou-se o seguinte caminho metodológico até chegarmos às respostas:

O presente estudo se baseou na abordagem qualitativa por ser isso que busca a explicação dos fenômenos através das relações dos mesmos. Santana (2008, p. 25-35) afirma que o objetivo central da fenomenologia "é compreender o fenômeno para dizer como funciona, e não para explicar seus motivos últimos e políticos”. O Tipo de estudo Explicativo, ele registra, analisa e interpreta fenômenos estudados, procurando identificar suas razões, seus fatores determinantes, suas causas. Embora esteja mais sujeita a erros, é o tipo de pesquisa que aprofunda o conhecimento. Caracterizada como exploratória, é o tipo de pesquisa que explica determinado fato, através da delimitação do estudo, levantamento bibliográfico, leitura e análise de documentos. Seu desenho, o estudo de caso, abordagem metodológica de investigação especialmente adequada quando procuramos compreender, explorar ou descrever acontecimentos e contextos complexos, nos quais estão simultaneamente envolvidos diversos fatores. As Fontes da Pesquisa compunham um universo de 10 (dez) professores de ensino superior de uma Faculdade, em diversos cursos superiores, questionando-os e entrevistandoos sobre a metodologia de uso da autoavaliação em sala de aula, caracterizando o grupo focal, escolhidos aleatoriamente.

O universo selecionado aleatoriamente foram 10 professores. Dentre os 10 , escolhemos 03 aleatoriamente, mesclando quem de fato, após análise dos questionários, teria mais afinidade com a autoavaliação na lógica pretendida pela pesquisa. Aplicamos os questionários face a face a cada um dos 10, e posteriormente coletamos os dados das entrevistas, através de gravação, ora descritos neste texto.

Sobre os Questionários e Entrevistas: Foi aplicado um (1) questionário elaborado previamente com 11 (onze) perguntas fechadas e abertas, estruturado em consonância com os objetivos pretendidos pela pesquisa, e uma (2) entrevista com 06 (seis) perguntas semiestruturadas, também elaborada previamente, gravada em arquivo MP3 e transcrita literalmente em aplicativo Microsoft Word 2007®. 
Além das 06 perguntas que permearam em respostas próximas dos objetivos da pesquisa, nós pedíamos aos 03 professores seletos que apresentassem instrumentos impressos de autoavaliação para explicar. Esta questão está relacionada ao objetivo comparar modelos de autoavaliação, através da análise documental.

Foi assim que encontramos a prática avaliativa do diário de bordo, por um professor do curso de análise de sistemas, sexo masculino, 32 anos, mestre em ciências da computação, que em seu depoimento coletado "faz diferente" do que fizeram a ele, empoderando o estudante na sua carreira de formação profissional.

\section{Resultados e Discussões}

Primeiramente vamos registrar aqui, todas falas em cima das perguntas feitas ao professor durante a entrevista, posterior à coleta de dados através de questionário, em que o mesmo sinalizou o uso desta prática homônima e consequentemente das considerações ditas sobre a temática da AUTOAVALIAÇÃO e o que seria o caminho feito com o diário:

1.0 que você pensa sobre autoavaliação?

Resposta do Professor: autoavaliações, de maneira periódica mesmo, é, passa uma parte do semestre onde há alguma aula, algum conteúdo, eu tenho as minhas anotações, eu chamo os alunos para conversar, é meio que, um bate papo mesmo,/II Aí a gente vai conversando, eu vou extraindo deles,// é enxergar-se, entender-se enquanto ativo nesse processo de aprendizado e no final conseguir mensurar isso.

2.De que maneira a autoavaliação colabora na sua maneira de avaliar? Resposta do Professor: o quanto que ele é quantitativamente e qualitativamente ele evoluiu no conteúdo, para mim me tira os $100 \%$ do peso da responsabilidade de botar uma nota para esse cara no sistema,// E a gente só consegue dividir essas responsabilidades se esse aluno consegue evoluir, //

3.Quais são os modelos de autoavaliação utilizadas por você em sala de aula? Resposta do Professor: É muito papo, sabe,// avaliação contínua, contínua, é o tempo todo, o tempo todo essas conversas acontecem,// faço Relatórios né, são questionários mesmos, 5, 6 perguntas tipo pesquisa de satisfação // UM DIÁRIO DE BORDO, é um texto livre, meu, em relação a observação com a turma, tá, é como se fosse uma ata mesmo, de aula, termina, a disciplina, a aula, geralmente eu faço ali, em casa ou por semana, dependendo muito também do volume de trabalho que demanda, mas eu nunca deixo de fazer, aí as minhas percepções, em relação aquele momento, como eu fui, o que é que aconteceu, como a turma reagiu, no coletivo e individual. 
4.Em quais momentos da trajetória de ensino você escolhe a autoavaliação? Por que razões?

Resposta do Professor: Porque cara, é, porque eu sofri (risos), pra aprender,// o mundo que tinha fora da sala de aula, pra eu aprender, seja o jardineiro aguando o jardim, uma pessoa carregando alguma coisa, um grupo de pessoas se reunindo, eu ficava observando aquilo enxergando - poxa ali fora também tem coisas pra eu aprender, né, não só aqui dentro, e a sala de aula,// então é basicamente entender que esse processo é tentar entender o aluno, se aproximar, ter uma empatia, com o seu aluno, ter uma proximidade, mas eu já trato eles como igual,// sempre sempre...

5.Qual a razão de considerar a autoavaliação importante para seus estudantes? Resposta do Professor: Autoconhecimento. Autoconhecimento. A satisfação de ver o aluno entrar de um jeito e sair modificando,

6.Durante a prática (aplicação) da autoavaliação o que se observa?

Resposta do Professor: Muitos tem dificuldade né, na maioria, porque você não gosta de olhar pra si, né, acho que é meio do ser humano né, você gosta mais de olhar pro outro,// //digamos que este seja um ponto negativo né, não se reconhecer...// é sim, não se reconhecer, //

Percebe-se diante da análise desse estudo averiguar qualitativamente o quanto o professor concebe a autoavaliação da aprendizagem (VARGAS, 1998). Ela é considerada como prática cotidiana nas atividades docentes, pois a cultura da autoavaliação envolve todos os atores configurando todos para o olhar para si e para o outro.

Por ser um recorte de um estudo que envolveu 10 (dez) professores e dentre estes, a seleção de 3 (três) e especificamente 1(um, descrito acima) que pratica o uso do diário de bordo, podemos refletir sobre esta prática que:

É desta forma, neste ponto, que a autoavaliação tem uma intensa finalidade: preparar para promover (VILLAS BOAS, 2008). Saber averiguar, compreender e propor são pontoschave dessa modalidade avaliativa. Ao utilizar a autoavaliação em relação aos estudantes, dando-os o protagonismo de demonstrar como possam fazer essa avaliação é importante para o olhar de quem recebe não somente o prédio e os equipamentos necessários para o desenvolvimento, como também, necessário que eles mesmos busquem alternativas próprias para o desenvolvimento intelectual nas suas relações de ensino e aprendizagem, no seu autoconhecimento, juntamente com quem diretamente se relacionam - os professores.

Quando se percebe a motivação do professor em relação às respostas dos estudantes se entende que a sala de aula é a realidade deste universo, dentro de universos maiores: professores, alunos e instituições. Embora tenha suas possibilidades de se compreender através da autoavaliação, faz-se necessário entender nas unidades menores (aluno, professores) como se dá esse processo, que qualidade se busca quando professores e alunos 
participam de seus fazeres ensinar-aprender-transformar (PERRENOUD,1999), (RÉGNIER, 1999), (HADJI, 2001) e (FERNANDES, 2009). Por outro lado, há professores que, por não ter a habilidade para as novas competências para o ensino e a aprendizagem, voltados aos novos tempos, acabam em cantos escuros e sem soluções. A autoavaliação é a ferramenta útil para a saída da 'escuridão', já que revela pontos de partida, chegada e pontos de intervenção nessa prática avaliativa. E felizmente, boa parte dos docentes não está no 'escuro' e sim certo do que está trabalhando e construindo novas metodologias e novos caminhos para a avaliação brasileira.

É importante observar, através dos dados que, mesmo professor de ensino superior, professores reflexivos, talvez pela natureza de um espírito científico (sem menosprezar os níveis educacionais anteriores), seja pela própria formação acadêmica, já que a mais tempo de trabalho e formação profissional ou apenas compreender e encarar que as respostas são apenas os resultados em busca da própria tomada de decisões como diziam Diago e Arredondo (2009), conforme se dá a nova tendência da avaliação educacional. Tais atitudes reflexivas dos docentes demonstram a maturidade e a certeza da escolha avaliativa em relação ao não se incomodar em dividir com o estudante este processo avaliativo.

Havendo mais momentos dos tipos "nós fazemos" do que "eu faço" - como realmente posso parar para pensar em si? Refletir a minha prática de estudante? E o professor à colher estes dados também pode - e deve - utilizar da mesma lógica avaliativa: Meus objetivos estão sendo atingidos? Meu estudante realmente aprende? Como se pode valorizar esta maneira de avaliar, além de tantas outras? Eis o desprendimento e a sinceridade docente e discente: melhorar ensino e concomitantemente as aprendizagens: no ensinar, no aprender. A avaliação diagnóstica é de fato inicial e voltada para a satisfação logo no ponto de partida. Formativa, quando o professor juntamente com os estudantes utiliza processos mediante dados coletados e analisados por um ou ambos, com sentido voltado para a aprendizagem contínua ou processual, em vias de se chegar a um resultado final, a chamada avaliação somativa (HOFFMANN, 1993) e, na maioria dos casos, uma avaliação de processo, autoavaliativa, e consequentemente de muito êxito ao final dos cursos. 


\section{Considerações Finais}

Comprova-se através do investigado acima uma grande vitória: Transpor essa lógica "formal”, excluída do processo é a forma de reconstruir a ótica em relação aos melhores resultados. Mas o professor é responsável por isso ao estudar mais como fazê-la e o estudante também ao ser sincero e colaborar com o processo.

O registro de tudo e a observação atenta do docente constrói o instrumento de avaliação, numa metáfora interessante - ao plano de voo. Do comando de subida à aterrisagem do avião. $\mathrm{O}$ input output do estudante, não apenas em relação à aprendizagem de conteúdos como também valores, procedimentos e consequentemente competências humanísticas muito importantes para o desenvolvimento educacional do país.

A avaliação tem sido uma atividade central da prática pedagógica, onde avaliar o ensino e a instituição educacional como um todo é uma necessidade pedagógica presente em todos os níveis educacionais independente de status de ensino básico até superior. Ensinar e aprender são a mesma face da moeda e devem andar em sintonia, alinhadas, por isso, conforme exposto acima, a ótica positiva e afirmativa da eficiência e eficácia da ferramenta "autoavaliação", dividindo as responsabilidades entre seus atores, e acima de tudo, do professor e do estudante como aprendizes de avaliação, já que aquele é consequência deste e vice-versa. Quisera afirmar, que todos os professores deste país planejassem e registrassem com toda eficiência e eficácia seu diário de bordo, transformando a realidade educativa do Brasil. Eis o desafio de cada professor, eis o desafio de cada estudante da área da educação.

\section{Referências}

BLOOM, B. S. et all. Handbook of formative and summative evaluation of student learning. Nova York McGraw-Hill, 1971.

BRANDALISE, M. A. T. Autoavaliação de escolas: alinhavando sentidos, produzindo significados. Ponta Grossa-PR: Editora UEPG, 2010.

CONDEMARÍN, M. MEDINA, A. Avaliação Autêntica: um meio para melhorar as competências em linguagem e comunicação. Porto Aletre: Artmed, 2005. 
DIAGO, J. C. ARREDONDO, S. C. Avaliação educacional e promoção escolar. Curitiba: IBPEX; São Paulo: Unesp, 2009.

ESTEBAN, M. T. Avaliar: ato tecido pelas imprecisões do cotidiano. In: Garcia, Regina Leite (org). Novos olhares sobre a alfabetização. São Paulo: Cortez, 2001.

FERNANDES, C. Indagações sobre currículo: Currículo e Avaliação. MEC- Ministério da Educação e Cultura. Secretaria da Educação Básica. Brasília: DF, 2008.

GIL, A. C. Como elaborar projetos de pesquisa. 4. ed. São Paulo: Atlas, 2002

GROCHOSKA, M.A. As contribuições da autoavaliação institucional para a escola da educação básica. Petrópolis: Vozes, 2013.

HADJI, C. A Avaliação desmitificada. Porto Alegre: Artmed, 2001.

HOFFMANN, J. Avaliação: Mito \& Desafio. Uma perspectiva construtivista. Porto Alegre: Educação e Realidade, 1993.

LAKATOS, E. MARCONI, M. Metodologia do Trabalho Científico. 6 ed. São Paulo: Atlas, 2001.

LUCKESI, C. Avaliação da aprendizagem escolar: apontamentos sobre a pedagogia do exame. In: Avaliação da aprendizagem escolar. São Paulo: Cortez, 1996. p. 17-26.

C. C. Avaliação da aprendizagem Escolar, 6 ed. São Paulo: Cortez, 1997.

C. C. Avaliação da aprendizagem na escola: reelaborando conceitos e recriando a prática. Salvador: Malabares Comunicação e Eventos, 2003.

C. C. Avaliação da Aprendizagem Escolar: estudos e proposições, 22 ed. São Paulo: Cortez, 2011.

MASETTO, M. Auto-avaliação em cursos de pós-graduação - Teoria e Prática. Campinas: Papirus, 2004.

PERRENOUD, P. Não mexam na minha avaliação! Para uma abordagem sistêmica da mudança pedagógica. In: Estrela. A. Nóvoa, A. (Orgs.). Avaliações em educação: Novas perspectivas. Porto, Portugal: Porto Editora LDA, 1993. p. 171-191.

PERRENOUD, P. Avaliação: da excelência à regulação das aprendizagens - entre duas lógicas. Porto Alegre: Artes Médicas Sul, 1999.

RÉGNIER, Jean-Claude. A autoavaliação na prática pedagógica. Avaliação, v.4, n.4 (14), 1999. p.45-53, dez. 
SANTANA, P. E. A. Uma breve análise didática dos métodos científicos positivismo, materialismo histórico e fenomenologia. Revista Cesumar - Ciências Humanas e Sociais Aplicadas jan./jun., v. 13, n. 1, 2008. p. 25-35.

VILLAS-BOAS, B. M. de F. Planejamento da avaliação escolar. Pró-posições, v. 9, n. 3, 1998.p. 19-27.

VILLAS-BOAS, B. M. de F. Avaliação formativa: em busca do desenvolvimento do aluno, do professor e da escola. (2008:51). In: Veiga, I. P. A. (Org.). As dimensões do projeto político-pedagógico. Campinas: Papirus, 2001. p. 175-212.

\section{Como citar este artigo (Formato ABNT):}

LOPES, Ivan do Nascimento F. A Prática da Autoavaliação no Ensino Superior. Id on Line Revista ultidisciplinar e de Psicologia, 2018, vol.12, n.39, p.839-850. ISSN: 1981-1179.

Recebido: 31.01 .2018

Aceito: 01.02.2018 